\title{
Ajuste fiscal no Brasil: algumas considerações de caráter pós-keynesiano
}

\author{
SÉRGIO WULFF GOBETTI* \\ ADRIANA MOREIRA AMADO
}

\begin{abstract}
(2)
Fiscal adjustment in Brazil: Some considerations under a post Keynesian approach. The article analyses the main issues concerned to fiscal policy in Brazil. For doing so, it assumes a Post Keynesian approach on this issue. First, it observes the origins of the Brazilian fiscal crises, showing that the Brazilian external debt had a fundamental role to play in its configuration. After, it analyses the present conduction of the fiscal policy in Brazil, emphasizing the orthodox framework that support it. Finally, the Post Keynesian approach on fiscal policy and the role of the State, as an element essential to reach a greater economic stability is discussed, showing that there are several experiences that seems to have a Keynesian bias, but that has little relation to Keynes approach, as is the case of Brazil.
\end{abstract}

Keywords: fiscal policy in Brazil; post keynesian theory; target regimes.

JEL Classification: B22; B50; H11; H62.

\section{INTRODUÇÃO}

Este artigo busca analisar a origem da crise fiscal brasileira e a natureza teórica, as características e a sustentabilidade da política fiscal brasileira, sobretudo a partir da adoção formal de metas de superávit primário, em 1999. Partindo de uma abordagem pós-keynesiana, queremos mostrar que a inspiração do ajuste fiscal posto em prática é eminentemente ortodoxa, embora recentemente tenham sido adotados mecanismos de cunho keynesiano, como o PPI e o PAC, cujos efeitos ainda são limitados.

\footnotetext{
* Doutor em Economia e técnico de planejamento e pesquisa do IPEA-Diretoria de Estudos Macroeconômicos. E-mail: swgobetti@gmail.com; Professora do Departamento de Economia da Universidade de Brasília. E-mail: uctpama@unb.br. Submetido: Maio 2008; Aprovado: Junho 2009.
} 
A defesa de equilíbrio orçamentário, por si só, não é incompatível com o pensamento de Keynes, mas sim os pressupostos e proposições que costumam acompanhar as políticas de ajuste fiscal colocadas em prática no Brasil. Ao contrário do senso comum que se formou entre os economistas ortodoxos, a crise fiscal não tem origem no desequilíbrio primário entre despesas e receitas, embora essa tenha sido uma das características das contas públicas durante um determinado período posterior à transição democrática, principalmente pela expansão das despesas da seguridade social ou do que denominamos welfare state brasileiro.

A introdução do regime de metas e a obtenção de expressivos superávits primários desde 1999 não alterou a dinâmica de crescimento desse tipo de transferências, o que implicou considerável aumento da carga tributária e redução dos investimentos públicos, além de extração de recursos das empresas estatais, como veremos em mais detalhes na seção dedicada à análise dos determinantes do ajuste fiscal. No governo Lula, essa tendência se acentuou com a decisão de aumentar o superávit primário e proporcionar aumentos reais do salário mínimo, ao qual está vinculada a maior parte das despesas da seguridade. Além disso, a ampliação dos programas de transferências de renda também criou um fator de pressão sobre as despesas correntes.

Essa dita prioridade "social" e a recente inflexão na política fiscal, com a criação do PPI e, mais recentemente, o lançamento do PAC, se deu sem romper com os fundamentos ortodoxos da política econômica, como a autonomia e a política restritiva do Banco Central na definição da taxa de juros com base em modelos neoclássicos que assumem a neutralidade da moeda. Essa falta de coordenação entre as políticas monetária e fiscal onera as contas públicas, pelo impacto dos juros sobre a dívida pública, em um circuito que alguns economistas denominam "dominância monetária" e que uma ministra do governo Lula chamou de "enxugar gelo". ${ }^{1}$

\section{ORIGEM DA CRISE FISCAL BRASILEIRA}

Nas últimas três décadas, formou-se um quase consenso entre economistas brasileiros de natureza ortodoxa de que o déficit fiscal é um dos problemas crônicos que estaria na raiz dos desequilíbrios internos e externos que impediriam o país de crescer. Esse diagnóstico parte de um fato incontestável da realidade, a deterioração da conta corrente das três esferas de governo, cujo sinal mais relevante é a queda da poupança pública de 5,46\% do PIB em 1970 para

\footnotetext{
${ }^{1}$ Dilma Roussef, ministra-chefe da Casa Civil, em entrevista ao jornal O Estado de S. Paulo, em 9 de novembro de 2005, ao criticar a proposta de ajuste fiscal do então ministro da Fazenda, Antônio Palocci, que previa um novo aumento da meta de superávit primário: "Para a dívida pública não crescer, é preciso ter uma política de juros consistente, porque senão você enxuga gelo. Faço um superávit primário de um lado e aumento o fluxo e o estoque da dívida por outro” [OESP, 2005, p. B01]
} 
- 8,62\% do PIB em 1985, ou seja, uma variação negativa de 14,08 pontos porcentuais. Embora essa queda da poupança tenha sido parcialmente revertida ao longo do Plano Real para algo em torno de - 2,5\% do PIB, mantemos uma diferença de 7 pontos porcentuais em relação ao início dos anos 1970 .

Há, entretanto, uma grande diferença entre reconhecer esse fato da realidade e assumir, como faz a teoria ortodoxa, que um desmesurado gasto público seja a principal causa da crise fiscal e da elevada taxa de juros. Parte desse equívoco decorre de uma análise distorcida das origens da crise fiscal e, sobretudo, da falta de compreensão sobre a natureza política e econômica do processo de ajustamento e transformação pelo qual passou o Brasil desde a ditadura até a transição para a democracia. Franco (1995), por exemplo, argumenta que a crise fiscal tem duas raízes: uma externa, que remonta à ruptura do padrão de financiamento externo no início dos anos 1980, e uma outra doméstica, associada à descompressão de demandas sociais e corporativas e à remodelagem do pacto federativo no início do regime democrático. $\mathrm{Ou}$ seja, embora reconheça formalmente "duas raízes", Franco segue o padrão analítico de outros economistas ortodoxos, concentrando seu foco sobre a segunda causa (interna) e de modo desconectado da primeira (externa), que na verdade também tem sua vertente doméstica.

De modo mais claro, por exemplo, Simonsen (1989) avalia que a crise da dívida externa do início dos anos 1980 justifica "apenas em pequena parte" a piora da conta corrente do setor público, argumentando que o "verdadeiro drama" foi provocado pela perda de receita tributária com o efeito Tanzi e pelo aumento das despesas de custeio a partir da redemocratização.

Por outro lado, Bresser-Pereira \& Dall'Acqua (1991) relacionam os déficits fiscais do Brasil à "política fiscal frouxa nos países latino-americanos” dos anos 1970 e 1980. Ou seja, o déficit fiscal estaria associado tanto ao "populismo econômico" de governos que tentam usá-lo com o objetivo de alcançar maior distribuição de renda e crescimento, quanto às políticas desenvolvimentistas implementadas com base na obtenção de empréstimos externos. ${ }^{2}$

O diagnóstico das Contas Nacionais do setor público que detalhamos na Tabela 1 mostra que, de modo diverso da crença enraizada, a crise fiscal brasileira não tem sua origem primária em um desequilíbrio entre receitas e despesas correntes do governo, até porque o consumo das administrações públicas se manteve estabilizado em torno de $10 \%$ do PIB até meados dos anos 1980 . A elevação das despesas (como proporção do produto) só ocorreu no período posterior, e como decorrência da crise gerada pela socialização do ônus do

\footnotetext{
${ }^{2}$ Bresser-Pereira \& Dall'Acqua (1991) dizem que o populismo econômico foi legitimado por "um certo tipo de keynesianismo que dá ênfase exclusiva à demanda efetiva, inverte a Lei de Say e advoga o uso indiscriminado da política fiscal e de déficits fiscais". Ou seja, uma visão de que basta impulsionar a demanda via gastos públicos para a oferta se ajustar.
} 
ajuste da dívida externa pelo qual passou a economia brasileira, no início dos anos 1980, como pode ser observado na Tabela 1.

Antes de esmiuçar esses dados, porém, lembremos que uma característica central do processo de endividamento externo do Brasil, como destaca Werneck (1986), foi a chamada estatização da dívida, que levou o setor público a gradativamente tornar-se responsável por cerca de $80 \%$ da dívida externa. O endividamento foi o caminho ao qual o governo recorreu, sobretudo depois do choque do petróleo, em 1974, para manter a economia em crescimento e viabilizar o equilíbrio do balanço de pagamentos. ${ }^{3} \mathrm{O}$ fato de os empréstimos terem sido contraídos pelas estatais adveio, inicialmente, da mera decisão de explorar as vantagens comparativas desse setor na captação e, posteriormente, da decisão de socializar o risco cambial envolvido nos novos empréstimos. Também merece recordação o fato de que o governo brasileiro, além de cercear de forma crescente o acesso das empresas estatais a fontes de financiamento internas (como o mercado de ações), também adotou uma política pouco realista de reajuste de preços e tarifas dos bens e serviços por elas produzidos, o que não só reduzia a sua capacidade de autofinanciamento, como era cômodo do ponto de vista da política anti-inflacionária.

De acordo com Coutinho \& Belluzzo (1984, pp. 162-163), a política macroeconômica ao longo de II PND é repleta de contradições, como a tentativa de compensar a expansão do crédito externo com o aperto no crédito lastreado em fontes internas. Quando sobreveio a crise cambial, em 1982, o padrão de financiamento do serviço da dívida externa, pela sua própria expansão, tornou-se inviável, obrigando o setor público a absorver todo o ônus do ajustamento externo. Reproduzindo a metodologia de Werneck (1986), isso pode ser verificado pelo brutal crescimento das transferências unilaterais (TU) e rendas líquidas enviadas ao exterior (RLEE), assim como pela decomposição da renda nacional disponível bruta (RNDB) entre o setor público e privado. Como se sabe:

$$
R N D B+R L E E+T U=P I B
$$

A Tabela 1 mostra como a RNDB encolheu em proporção do PIB entre 1970-74 e 1980-84 fruto das transferências de recursos ao exterior (RLEE + TU). Mas os dados indicam que esse encolhimento se deu apenas no setor público, aqui compreendido como o somatório das administrações públicas, excluindo as empresas estatais.

A RNDB do setor público caiu de $15,97 \%$ do PIB para $9,12 \%$ no período analisado, chegando a 1,13\% em 1985-1989. Os dados também mostram que esse ajuste se deu pela deterioração das receitas, pelo aumento dos subsídios,

\footnotetext{
${ }^{3}$ Cruz (1984) mostra que, inicialmente, o processo de endividamento externo apenas serviu para absorver a liquidez internacional de eurodólares, não se justificando do ponto de vista das contas externas.
} 
das transferências previdenciárias e assistenciais e, sobretudo, pelo vertiginoso crescimento dos dispêndios com juros sobre a dívida interna, que passaram de $1,20 \%$ do PIB, em média, entre 1970-74, para 3,83\%, entre $1980-84$, e para $14,95 \%$, entre $1985-1989$.

Tabela 1 Decomposição da Renda Nacional Disponível, com ênfase no setor público (\% do PIS)

\begin{tabular}{l|c|c|c|c|c}
\hline Componentes & $1970-74$ & $1975-79$ & $1980-84$ & $1985-89$ & $1990-94$ \\
\hline RLEE + TU & 0,89 & 1,90 & 5,01 & 4,30 & 2,14 \\
Renda disponível do setor privado & 83,14 & 84,84 & 85,87 & 94,56 & 90,37 \\
\hline Renda disponível do setor público* & 15,97 & 13,26 & 9,12 & 1,13 & 7,48 \\
\hline Carga Tributária & 25,47 & 25,25 & 25,39 & 24,33 & 27,01 \\
Outras receitas correntes líquidas & $(0,11)$ & $(0,93)$ & $(1,18)$ & 1,32 & 3,68 \\
(-) Subsídios & $(1,12)$ & $(1,91)$ & $(2,75)$ & $(1,65)$ & $(1,70)$ \\
(-) Transferências previdenciárias & $(7,07)$ & $(7,42)$ & $(8,51)$ & $(7,92)$ & $(9,95)$ \\
e assistenciais & $(1,20)$ & $(1,74)$ & $(3,83)$ & $(14,95)$ & $(11,55)$ \\
(-) Juros da dívida pública interna & 10,49 & 9,94 & 9,71 & 12,64 & 15,62 \\
\hline Consumo das administrações públicas & 7,60 & 6,95 & 6,70 & 8,40 & 9,43 \\
\hline Salários e Encargos & 2,88 & 2,98 & 3,01 & 4,23 & 6,18 \\
\hline Outras compras de bens e serviços & 5,49 & 3,33 & $(0,59)$ & $(11,50)$ & $(8,13)$ \\
\hline Poupança das administrações públicas
\end{tabular}

Fonte: IBGE(SCN 1970-1995)

(*) Exclui empresas estatais, que estão no setor privado.

Apesar do maior espaço de inversão ocupado pelas estatais, os dados reunidos por Werneck (1986) não confirmam a suspeita de que as empresas federais tenham absorvido transferências significativas de recursos do restante da economia e os tenham desperdiçado em folhas de pagamento inchadas. $\mathrm{Ou}$ seja, o ônus suportado pelo setor público - no sentido amplo, incluindo as estatais - é maior e não menor do que o revelado pelas Contas Nacionais quando nos restringimos às esferas governamentais.

De qualquer forma, o mais importante é que esse diagnóstico coloca luzes sobre a verdadeira natureza do déficit fiscal brasileiro, que não é - pelo menos no momento inicial - o excesso de gastos correntes ou de concessões às demandas sociais, inspiradas em "um certo tipo de keynesianismo", como sugerido por Bresser-Pereira \& Dall'Acqua (1991). O "populismo econômico" brasileiro não se baseou em um paradigma distributivo; como mostram os dados revelados por Barros et ali. (2001), a concentração de renda foi uma característica central do processo de crescimento dos anos 1970. Logo, não é 
surpresa que esse modelo de crescimento, condicionado pelos interesses privados, tenha gerado uma crescente pressão social por reformas e pela criação de estruturas de welfare state, a exemplo da Europa no pós-guerra.

O processo de redemocratização do Brasil marca uma inflexão na evolução do chamado consumo das administrações públicas. Depois de mais de uma década estabilizada em torno de $10 \%$ do PIB, a despesa das três esferas de governo com pagamento dos servidores públicos ativos e com compras de bens e serviços chegou a $15,5 \%$ do PIB em 1989, ao final do governo José Sarney. A folha salarial do funcionalismo, especificamente, cresceu de $6,28 \%$ do PIB em 1984 para 10,51\% em 1989. Parte desse processo de expansão das despesas correntes, como proporção do PIB, se explica pela desaceleração do crescimento econômico, que caiu de $8,6 \%$ ao ano, em média, na década de 1970 , para 1,6\% nos 1980 . Isso, obviamente, fez o denominador da relação despesa-PIB praticamente estacionar nessa década. Mas, de fato, os gastos do governo, ao contrário da economia, aceleraram-se a partir da transição de regime político, em 1985.

Isso pode ser melhor visto na Tabela 2, que reproduz a variação real dos gastos das administrações públicas por quinquênio. Entre 1974 e 1979, as despesas de pessoal e as compras do governo crescem $44,7 \%$, enquanto o PIB expande $36,4 \%$ em termos reais, utilizando o deflator do PIB para atualizar os valores nominais. ${ }^{4}$ No quinquênio seguinte (1979-84), marcado por uma fase recessiva, os gastos do governo permanecem praticamente congelados em termos reais, enquanto o PIB cresce apenas 7,9\%. Já nos cinco anos seguintes, que coincidem com o mandato do ex-presidente José Sarney (1984-89), os gastos da administração pública chegam a crescer $108,5 \%$, ante uma expansão econômica de $23,7 \%$.

Ou seja, configura-se claramente uma fase expansionista dos gastos públicos a partir da segunda metade dos anos 1980, que coincide com a elevação dos patamares de inflação e também dos custos de rolagem da dívida pública. Essa fase de expansão tem um novo repique no início dos anos 1990, associado à expansão das despesas da Previdência depois da Assembleia Constituinte de 1988. Mas é preciso analisar esse fenômeno levando em consideração que o período anterior da história brasileira foi marcado por uma condução da política econômica que privilegiou o setor privado e acentuou as desigualdades sociais. Dessa forma, o quadro de crise fiscal originado da crise da dívida externa agrava-se enormemente com a redemocratização e o surgimento tardio de uma estrutura de welfare state, cujo financiamento não foi devidamente equacionado.

\footnotetext{
${ }^{4}$ As transferências previdenciárias apresentam um crescimento de $75 \%$ entre 1974 e 1979, bem superior à expansão do PIB, porque na série do IBGE o ano de 1974 registra o menor nível para essa despesa, 6,08\% do PIB, ante $8,21 \%$ do PIB em 1970. Ou seja, a expansão se explica em parte pela retração do período imediatamente anterior.
} 
Tabela 2: Expansão real dos gastos públicos e do PIB, por quinquênio

\begin{tabular}{|c|c|c|c|c|c|}
\hline Período & Consumo & Pessoal & Compras & Transf. Prev. & PIB \\
\hline $1974-79$ & $44,7 \%$ & $46,8 \%$ & $39,9 \%$ & $75,0 \%$ & $36,4 \%$ \\
\hline $1979-84$ & $0,2 \%$ & $-3,1 \%$ & $8,1 \%$ & $19,2 \%$ & $7,9 \%$ \\
\hline $1984-89$ & $108,5 \%$ & $107,3 \%$ & $111,2 \%$ & $16,5 \%$ & $23,7 \%$ \\
\hline
\end{tabular}

Fonte: Elaboração própria, a partir de dados do IBGE (SCN 1970-1995)

(*) Consumo do governo se desdobra em despesas de pessoal e compras de bens e serviços

Apesar de o monitoramento do FMI sobre o déficit fiscal brasileiro remontar à primeira carta de intenções assinada com o Fundo, em 1983, a implementação do ajuste fiscal, incluindo a primeira fase do Plano Real, seguiu uma trajetória instável até a negociação fechada no final de 1998 com o Fundo, que inaugurou a adoção formal de metas de superávit primário para o setor público. Originalmente, os programas de ajustamento de balanço de pagamentos do Fundo previam apenas metas de contenção do crédito interno líquido, para reduzir o consumo e reequilibrar as contas externas. Em várias experiências de ajustamento, entretanto, o Fundo constatou que as metas para crédito eram atingidas, mas com expressivo crescimento da emissão de títulos públicos, o que, de acordo com a abordagem neoclássica, provocaria crowding out. Por isso, o FMI também passou a monitorar a política fiscal a partir de metas.

Conforme argumenta Biasoto Jr. (2006, p. 197), tanto a escolha do tipo de indicador fiscal a ser monitorado, quanto da sua abrangência no setor público, "guardam relação estreita com as concepções sobre a atuação estatal e as noções quanto ao impacto macroeconômico das contas públicas". No caso brasileiro, por exemplo, a escolha do critério primário, que exclui os juros do cálculo, é revelador da opção por blindar a política monetária contra ações discricionárias do governo, o que, como veremos mais adiante, teve profundas consequências sobre a trajetória do ajuste fiscal do país.

A adoção de metas formais de superávit primário concomitantemente a metas de inflação, com autonomia operacional do Banco Central para definir a taxa básica de juros, como ocorreu no Brasil a partir de 1999, teve consequências práticas e teóricas importantes. A primeira delas é que, do ponto de vista macroeconômico, o governo abdicou da política fiscal e monetária como instrumento de indução do crescimento ou de estabilização da demanda agregada, o que claramente atende ao paradigma novo clássico, que considera tais políticas inflacionárias.

Embora Averbug \& Giambiagi (2000, p. 24) justifiquem a decisão de usar uma meta de superávit primário no lugar de uma meta de déficit nominal por uma questão pragmática, qual seja, "a dificuldade de adivinhar com certa precisão o comportamento futuro dos juros", o modelo em questão pressupõe que a autoridade fiscal nada possa fazer quanto à trajetória da taxa de juros, a não ser prevê-la. Tal pressuposto deriva-se da tese de que o regime de metas de 
inflação, com uma regra de Taylor, maximiza o bem estar da sociedade, sendo superior a qualquer política discricionária.

Em segundo lugar, quando o objetivo central da política econômica passa a ser a estabilização inflacionária, a política fiscal não só deixa de ser ativa como se torna dependente da política monetária, ou seja, exige-se que as metas de superávit primário sejam ajustadas permanentemente aos aumentos na taxa de juros para evitar que a dívida pública se eleve como proporção do PIB. Foi isso precisamente que ocorreu no início do governo Lula, quando as metas de superávit primário foram elevadas de $3,75 \%$ para $4,25 \%$ do PIB para compensar o aumento dos juros e tentar reverter as expectativas dos agentes econômicos.

Em meados de 2005, inspirados na proposta de Delfim Netto (2005), inúmeros economistas passaram a defender que a meta fosse novamente elevada para $5 \%$ do PIB, com o argumento de que isso contribuiria para o "relaxamento gradual da política monetária" e "permitiria ao país atingir o famoso déficit zero" (Giambiagi, 2005). Apesar das críticas e ressalvas de economistas de outras matizes a essa proposta, o governo Lula seguiu-a parcialmente, na medida em que não alterou formalmente a meta, mas superou-a com folga nos três primeiros anos do mandato.

Não há evidências de que esse movimento fiscal tenha surtido os efeitos propalados, como podemos verificar no Gráfico 1. Com exceção de 1999, no início do programa de ajuste fiscal, o aumento de superávit primário não é acompanhado de redução nos juros reais. Em 2005, ao contrário, os juros crescem apesar do comportamento ascendente do superávit. Ou seja, no melhor das hipóteses, o superávit maior serviu para cobrir parcialmente o custo mais elevado da dívida provocado pela elevação dos juros e não contribuiu para sua posterior queda. Essa evidência sugere, como teoriza Smithin (1994, p. 151), que a relação causal entre os déficits ou superávits fiscais e a taxa real de juros "may be the opposite of that usually suggested in the conventional literature".

Gráfico 1: Gráfico 1 - Comparação entre superávit primário e juros reais (\% PIB)

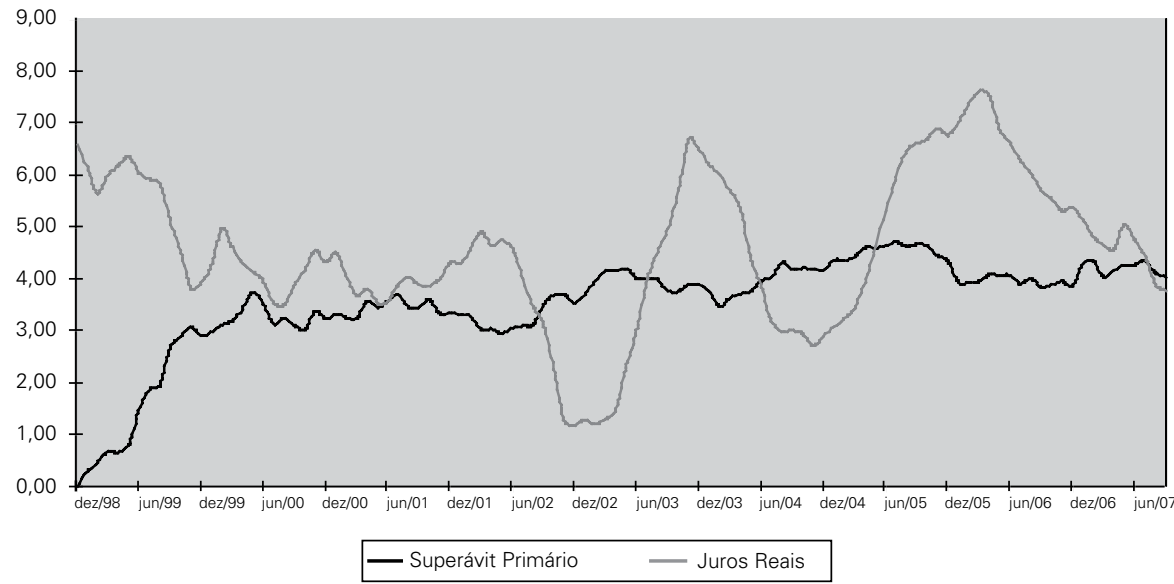


Outra importante implicação do modelo de monitoramento das contas públicas é que, tendo como metas o superávit primário e a dívida líquida do setor público, ele não impõe restrições à rolagem da dívida mobiliária bruta, apesar de a Lei de Responsabilidade Fiscal prever limites para a mesma, que nunca foram regulamentados. Isso significa que a elevação da dívida bruta, desde que acompanhada por elevação das disponibilidades, deixa de ser um problema aos olhos das autoridades fiscais e do FMI. E é isso exatamente que vinha ocorrendo com a administração da dívida pública interna até recentemente, ao menos.

De acordo com os dados do Banco Central, a dívida interna do governo geral cresceu de $48,60 \%$ do PIB em dezembro de 2002 para 59,44\% do PIB em setembro de 2007. No mesmo período, as disponibilidades do governo geral cresceram de $5,97 \%$ do PIB para $11,74 \%$. A maior parte dessas disponibilidades são recursos esterilizados do superávit primário que poderiam ser utilizados para resgatar títulos da dívida pública, mas permanecem depositados no Banco Central, sendo remunerados por uma taxa próxima à Selic, mas inferior à taxa de juros implícita sobre a dívida pública. ${ }^{5}$

A manutenção de tão elevado colchão de liquidez é mais um sintoma da dominância da política monetária sobre a fiscal. Se o Tesouro Nacional resgatasse seus títulos com as disponibilidades que possui, a liquidez da economia seria elevada na mesma proporção, pressionando a taxa de juros para baixo, a menos que o próprio BC interviesse no mercado para enxugar essa liquidez. Ou seja, o Tesouro é obrigado a administrar a dívida de modo a sancionar uma taxa de juros maior do que a exigida pela própria situação fiscal.

De acordo com Bresser-Pereira (2004, p. 14), a rolagem da dívida pública a altas taxas reais de juros tem sido mantida sob o pretexto de que, sem ela, o mercado não financiará os títulos, apesar de "sabermos que os grandes bancos que dominam esse mercado não têm alternativa de aplicação de curto prazo de seus recursos senão rolando os títulos públicos”. A razão para isso, segundo ele, é que "o BC deixou-se capturar internamente pelos rentistas ou capitalistas inativos e pelo sistema financeiro que vive das comissões ou taxas que recebe desses rentistas".

A expansão da dívida mobiliária, como observa Biasoto Jr. (2006), ocorre de modo concomitante ao aprofundamento do desmonte da estrutura de financiamento do setor público. A dívida contratual, ou bancária, por exemplo, segue em queda com reflexo direto de todas as restrições impostas ao endividamento dos estados, municípios e empresas estatais. Por outro lado, a adoção das metas de superávit primário e as restrições às operações de crédito no

\footnotetext{
${ }^{5}$ A remuneração cobre parcialmente o custo do Tesouro, mas gera prejuízo ao próprio BC. Para o setor público, portanto, o colchão de liquidez equivale, literalmente, a manter moeda debaixo do colchão. Abdica-se de abater a dívida mobiliária em decorrência da necessidade de enxugar a liquidez. Dessa forma, a política monetária tem um duplo custo fiscal: primeiro ao manter uma taxa de juros elevada, segundo ao exigir elevados montantes de emissão de títulos.
} 
âmbito estadual e municipal também implicaram considerável redução no patamar de investimentos públicos.

Isso decorre do fato de que, como assinala Biasoto Jr. (2006, p. 206), “o conceito de NFSP (Necessidade de Financiamento do Setor Público) é tão somente financeiro, o que faz com que não se leve em conta a destinação dos gastos que conduzem ao déficit". Dessa forma, "investimentos em nova capacidade produtiva em uma empresa estatal resultam em novo endividamento de forma indistinta que o derivado da expansão de gastos correntes. Ou seja, o conceito perde a dimensão de mudança patrimonial do Estado, o que, no caso brasileiro, é crucial" (Ibid).

O próprio Banco Mundial já detectou esse problema, como fica evidenciado em uma análise do economista Luis Servén (2004, p. 4): “Desde a década de 1980, a maioria dos países latino-americanos reduziu seus desequilíbrios fiscais, mas em vários países a disciplina fiscal também teve um custo em termos de inversão pública em infraestrutura”.

\section{OS DETERMINANTES DO SUPERÁVIT PRIMÁRIO (1999-2006)}

Os relatórios do BACEN sobre os resultados fiscais do setor público mostram que o superávit primário tem crescido entre 0,20 e 0,30 pontos porcentuais do PIB a cada ano desde 1999 com exceção de 2006, quando há uma leve inflexão nessa tendência. Em média, a segunda gestão FHC apresentou um superávit primário de $3,26 \%$ do PIB, enquanto o primeiro mandato de Lula registrou um superávit de $4,08 \%$ do PIB.

$\mathrm{Na}$ Tabela 3, apresentamos estimativas de decomposição do superávit primário do setor público entre receitas e despesas de modo a evidenciar os determinantes centrais do processo de ajuste fiscal. Num primeiro momento, como podemos perceber pelas médias de 1999-2002, as estatais contribuíram diretamente com $34 \%$ do aumento do superávit primário e, indiretamente, via royalties e dividendos pagos ao Tesouro, com mais $10 \%$; no período seguinte, 2003-2006, essa contribuição indireta das estatais se amplia em importância, enquanto a contribuição direta se estabiliza. Esse comportamento se explica por fatores endógenos e exógenos à política fiscal: endogenamente, uma vez atingida a meta de superávit das estatais, o governo opta por elevar seu próprio superávit por meio dos dividendos das empresas das quais é acionista majoritária; exogenamente, pelas condições do mercado externo e interno, principalmente na área petrolífera, que propiciaram considerável expansão dos royalties.

$\mathrm{O}$ dado mais relevante, entretanto, diz respeito ao efeito que o aumento das receitas e das despesas teve sobre o superávit primário. O aumento das receitas, por exemplo, teve um impacto de $266 \%$ (ou $207 \%$ excluindo os royalties e dividendos) sobre o aumento do superávit no governo Lula em comparação ao governo FHC, enquanto a elevação das despesas teve um peso negativo de $165 \%$ - $119 \%$ na esfera federal e $47 \%$ na subnacional. Entre as despesas, entretanto, há aquelas que também caíram, contribuindo para o re- 
sultado primário. $\mathrm{Na}$ esfera federal, por exemplo, as despesas de pessoal caíram 0,26 pontos porcentuais do PIB de 1999-2002 para 2003-2006, os investimentos outros 0,22 pontos porcentuais, e as demais OCC, 0,34 pontos porcentuais. Ou seja, esses três itens registram uma queda de 0,82 pontos porcentuais do PIB no primeiro mandato de Lula, valor quase idêntico ao aumento de superávit no período.

No caso dos investimentos e dos demais gastos de OCC, sobre os quais há maior discricionariedade, é possível identificar uma clara tendência de queda desde o início do ajuste fiscal, além de uma grande volatilidade ao longo dos mandatos. Em proporção do PIB, os investimentos federais situaram-se, no primeiro mandato de Lula, em um patamar 50\% inferior a 1998 e $30 \%$ inferior à média do segundo mandato de FHC. Tanto em um mandato quanto em outro, contudo, os gastos cresceram nos dois anos anteriores às eleições presidenciais.

Tabela 3:

Contribuição para o resultado primário, por esfera, receitas e despesas (\% do PIB)

\begin{tabular}{|c|c|c|c|c|c|c|c|}
\hline Esfera & $1998(A)$ & $1999-2002(\mathrm{~B})$ & $2003-2006(C)$ & $A \rightarrow B$ & $\%$ Tota I & $\mathrm{B} \rightarrow \mathrm{C}$ & $\%$ Total \\
\hline Estatais c/ Itaipu & $-0,33$ & 0,78 & 0,82 & 1,10 & $34 \%$ & 0,05 & $6 \%$ \\
\hline Receitas & 31,84 & 34,42 & 36,58 & 2,58 & $79 \%$ & 2,17 & $266 \%$ \\
\hline $\begin{array}{l}\text { Royalties } \\
\text { e dividendos }\end{array}$ & 0,13 & 0,45 & 0,92 & 0,31 & $10 \%$ & 0,48 & $59 \%$ \\
\hline $\begin{array}{l}\text { Demais receitas } \\
\text { federais }\end{array}$ & 18,61 & 20,06 & 21,26 & 1,45 & $45 \%$ & 1,20 & $147 \%$ \\
\hline $\begin{array}{l}\text { Receitas } \\
\text { subnacionais }\end{array}$ & 13,10 & 13,91 & 14,40 & 0,82 & $25 \%$ & 0,49 & $60 \%$ \\
\hline Despesas & 31,22 & 31,99 & 33,33 & 0,76 & $-23 \%$ & 1,34 & $-165 \%$ \\
\hline Federais & 15,04 & 15,13 & 16,08 & 0,09 & $-3 \%$ & 0,97 & $-119 \%$ \\
\hline Pessoal & 4,56 & 4,66 & 4,40 & 0,10 & $-3 \%$ & $-0,26$ & $32 \%$ \\
\hline $\begin{array}{l}\text { Presidência } \\
\text { e Assist.* }\end{array}$ & 6,05 & 6,34 & 7,99 & 0,28 & $-9 \%$ & 1,65 & $-203 \%$ \\
\hline Subsídios & 0,30 & 0,27 & 0,38 & $-0,03$ & $1 \%$ & 0,12 & $-14 \%$ \\
\hline Investimentos & 0,92 & 0,70 & 0,48 & $-0,22$ & $7 \%$ & $-0,22$ & $27 \%$ \\
\hline Demais OCC & 3,21 & 3,08 & 2,73 & $-0,13$ & $4 \%$ & $-0,34$ & $42 \%$ \\
\hline BACEN & 0,00 & 0,08 & 0,11 & 0,08 & $-3 \%$ & 0,02 & $-3 \%$ \\
\hline $\begin{array}{l}\text { Estados } \\
\text { e Municípios** }\end{array}$ & 16,19 & 16,86 & 17,25 & 0,68 & $-21 \%$ & 0,38 & $-47 \%$ \\
\hline $\begin{array}{l}\text { Discrep. } \\
\text { Estatísticas }\end{array}$ & $-0,27$ & 0,06 & 0,00 & 0,33 & $10 \%$ & $-0,06$ & $-7 \%$ \\
\hline Total & 0,01 & 3,26 & 4,08 & 3,25 & $100 \%$ & 0,81 & $100 \%$ \\
\hline
\end{tabular}

Fonte: Elaboração própria (origem primária dos dados: BACEM, STN, SIAFI, BEOE/FINBRA).

(*) Inclui LOAS/RMV, seguro-desemprego e abono salarial, Bolsa Família e as transferências a pessoas.

$\left({ }^{*}\right)$ Despesa dos governos subnacionais menos transferências voluntárias da União para Estados e Municípios. 
No caso das despesas de pessoal, é possível definir um padrão semelhante: ao longo do governo FHC, elas atingiram um pico, nos dois primeiros anos do governo Lula foram fortemente comprimidas, mas desde então vêm crescendo, voltando a se aproximar do patamar de 2001 e 2002. Aparentemente, a redução da despesa de pessoal como proporção do PIB, pelo menos na média de um período de governo, continua sendo uma fonte importante de poupança. Ou seja, do ponto de vista fiscal, há um ganho intertemporal quando o governo mantém os salários do funcionalismo parcialmente congelados durante a maior parte do mandato, mesmo que no último ano os reajustes reponham a inflação e ainda proporcionem um ganho real moderado.

Além disso, é importante salientar que o ganho fiscal decorrente da redução da despesa de pessoal como proporção do PIB só não é maior pela falta de controle do Executivo sobre os gastos dos demais poderes e pela lacuna existente na Lei de Responsabilidade Fiscal (LRF) no que se refere aos limites aplicáveis a esses poderes.

Por outro lado, o espaço fiscal aberto pela redução de OCC e Pessoal foi mais do que neutralizado pelos demais gastos, notadamente os subsídios e as transferências previdenciárias e assistenciais. Os subsídios aumentaram 0,12 ponto porcentual do PIB no governo Lula e as transferências a pessoas, 1,65 ponto porcentual. Entre as transferências estão não só os benefícios da Previdência, como também os da Lei Orgânica da Assistência Social (LOAS), os do Fundo de Amparo ao Trabalhador (seguro-desemprego e abono salarial) e o Bolsa Família. Ou seja, trata-se da rede de proteção social ou o que denominamos de welfare state brasileiro.

Ao contrário de outros tipos de gastos, que apresentam certa oscilação ao longo do ciclo eleitoral e sofrem os impactos do ajuste fiscal, os da rede de proteção social têm crescido em média cerca de $0,33 \%$ do PIB ao ano, nos últimos nove anos, com tendência de aceleração no governo Lula devido aos critérios recentemente adotados para reajuste do salário mínimo. Do total de transferências da Previdência e Assistência consideradas neste estudo, apenas as bolsas a pessoas físicas e algumas despesas do FAT não têm seu piso vinculado ao salário mínimo. De qualquer forma, todos os itens considerados como despesas previdenciárias e assistenciais têm crescido acima do PIB. Além disso, transferências que não existiam antes do início do ajuste fiscal foram criadas, como o Bolsa Família e os programas de transferência de renda que o antecederam.

\section{DÉFICITS PÚBLICOS E POLÍTICA FISCAL}

Após análise do ajuste fiscal brasileiro e de algumas considerações sobre a natureza teórica da questão fiscal e de seu ajuste no Brasil, fica a pergunta: será que a origem do problema fiscal relaciona-se com as ideias de Keynes, como proposto por alguns, quando criticam a expansão dos gastos correntes 
de governo? Para tanto, faz-se necessário recorrer às ideias daquele autor sobre a questão fiscal e observar se suas proposições guardam ou não proximidade com as questões colocadas neste artigo sobre o problema fiscal no Brasil e sobre as bases em que se deu seu equacionamento.

A busca de equilíbrio orçamentário por meio de superávit primário nas contas públicas tornou-se um paradigma dominante na configuração das políticas econômicas e fiscais de países em desenvolvimento que, como o Brasil, apresentam elevado grau de endividamento. Em termos históricos, o combate aos déficits públicos ressurgiu com mais força ao final dos anos 1960, em reação às quase quatro décadas anteriores de hegemonia das ditas políticas keynesianas e aos seus - alegados pela ortodoxia — efeitos inflacionários e/ou de endividamento público.

Grande parte das políticas fiscais expansionistas do período pós-guerra inspirava-se na posição de Keynes sobre a necessidade de o governo intervir na economia para manter a demanda efetiva em períodos de maior incerteza, em que os agentes privados revelam maior preferência pela liquidez e retraem seus investimentos. Além disso, segundo Keynes (1982, cap. 10), a política fiscal poderia ser usada como instrumento de distribuição de renda, potencializando o efeito multiplicador dos gastos públicos, por meio da tributação dos mais ricos e das transferências fiscais para as camadas da população com maior propensão a consumir.

Convém ressaltar, entretanto, que a Teoria Geral de Keynes é uma obra elaborada sob o impacto da grande depressão de 1929 e sob a base de uma nova concepção - distinta dos clássicos - a respeito de questões centrais para a teoria econômica, como a natureza da moeda e da própria economia capitalista. Em um artigo preparatório da TG escrito em 1932, denominado "A Monetary Theory of Production", por exemplo, Keynes sustenta que a falta de solução para a crise que se abatia sobre a economia mundial naquele momento decorria principalmente de falhas da teoria ortodoxa em compreender sua natureza e gerar instrumentos para a ação das autoridades, já que a maior parte dos economistas clássicos pensava na moeda como um mero facilitador de trocas.

Essa natureza não neutra da moeda num ambiente eminentemente incerto como o da economia capitalista foi incorporada ao princípio da demanda efetiva de Keynes para explicar o porquê das crises econômicas e do desemprego involuntário. Ao contrário do apregoado pela teoria de equilíbrio ortodoxa, de que forças naturais tenderiam a levar a economia de volta ao nível de pleno emprego, para Keynes o normal era que a economia capitalista operasse abaixo do seu nível ótimo, "exceto em períodos de guerra e de auge dos booms" (Keynes, 1973, v. 13, p. 407).

Carvalho (1999, p. 267) ressalta, entretanto, que as falhas do sistema econômica, por si mesmo, não são suficientes para justificar a intervenção do Estado. É necessário supor também que o Estado seja capacitado para lidar com esses problemas de uma maneira mais eficiente. Segundo Davidson (1991, 
pp. 73-74), não há por que acreditar que o governo fará melhores julgamentos sobre o futuro econômico do que o setor privado, mas o governo pode ter uma visão de mais longo prazo sobre as necessidades da comunidade, enquanto os indivíduos no setor privado estão mais motivados pelas oportunidades de lucro rápido. Logo, o Estado pode fugir das expectativas generalizadas na economia acerca das perspectivas de rentabilidade do capital e, ao agir assim, modificar o estado destas. ${ }^{6}$

Por isso, Keynes (1982, p. 163) entende que o governo pode "desempenhar um papel decisivo na determinação da escala das operações de investimento" em projetos de longo prazo. Isso não significa que o governo deva se envolver em microdecisões, nem implica que o Estado assuma o controle dos meios de produção.

"Eu entendo, portanto, que uma socialização algo ampla dos investimentos será o único meio de assegurar uma situação aproximada de pleno emprego, embora isso não implique a necessidade de excluir ajustes e fórmulas de toda a espécie que permitam ao Estado cooperar com a iniciativa privada. Mas, fora disso, não se vê nenhuma razão evidente que justifique um sistema de Socialismo de Estado. Não é a propriedade dos meios de produção que convém ao Estado assumir. Se o Estado for capaz de determinar o montante agregado dos recursos destinados a aumentar esses meios e a taxa básica de remuneração aos seus detentores, terá realizado o que lhe compete." (Ibid, p. 288)

Conforme Davidson (1999, p.75-6), o governo pode criar os ativos líquidos necessários para suprir a preferência pela liquidez do setor privado, sempre que ela é aguçada por incertezas sobre os rumos da economia, garantindo dessa forma o pleno emprego dos fatores de produção.

"It is the responsability of a civilized government to act as a balancing Wheel in maintaining industry's aggregate sales by using its fiscal powers - that is, its power to spend and to tax - to make sure that total market demand neither stagnates nor declines [...] If such government 'deficits' are undertaken on a proper scale in any given recessionary circumstances, this can generate sufficient profit opportunities to encourage businessmen to expand production and employ idle machinery and unemployed workers.” (Ibid, p. 77)

A coexistência de inflação, de desemprego e de déficits públicos nos anos 1970, entretanto, levou a ortodoxia a criticar o uso do ativismo fiscal como instrumento de estabilização da demanda. A crença hegemônica disseminada

\footnotetext{
${ }^{6}$ Ferrari Filho (2005) discute o papel da política econômica em Keynes ao longo de sua trajetória teórica.
} 
no meio acadêmico e entre os policymakers nos últimos 30 anos é que, se as políticas keynesianas chegaram a funcionar no passado, não mais serviriam para lidar com os problemas macroeconômicos da atualidade.

De acordo com Kregel (1985, pp. 30-35), a experiência dos países desenvolvidos nas décadas de 1960 e 1970 mostra que o valor real das transferências da seguridade social tenderia a crescer nos bons momentos da economia e manter-se constante nos maus tempos, contrariando a expectativa de Keynes sobre o seu comportamento contra-cíclico e, também, sobre seu papel como "estabilizadores automáticos". Contudo, o autor argumenta que esse resultado não expressa um fracasso da teoria keynesiana, mas sim uma falha em interpretá-la e de um atraso dos policymakers em reagir à crise econômica, como alertara Keynes (1980, v. 27, p. 316): "Much less effort is required to prevent the ball rolling than would be required to stop it rolling once it has started".

Mas há outro aspecto a considerar: embora admitisse o déficit como expediente temporário diante de situações de desemprego, Keynes (Ibid, p. 350) manifestava uma clara preferência por políticas preventivas, baseadas em um programa de investimentos públicos ou semipúblicos de larga escala e longo prazo, para estabilizar a renda, como propôs no pós-guerra. Nesse contexto, ele chega a propor que o orçamento seja dividido em duas partes, uma dos gastos correntes e outra dos gastos de capital (Ibid, pp. 277-80). O orçamento corrente representaria os gastos de consumo do governo e deveria estar sempre equilibrado ou superavitário. Já o orçamento de capital poderia ser equilibrado em longo prazo, com os próprios recursos que se espera obter da sua execução.

De acordo com Smithin (1989), o contexto em que Keynes elaborou suas ideias e a necessidade de obter apoio acadêmico às mesmas poderiam explicar, em grande medida, sua preocupação com a necessidade de manter o orçamento corrente equilibrado e mostrar a viabilidade do equilíbrio de longo prazo do orçamento de capital:

"It can immediately be seen that deficit financing of state capital spending is much easier to defend politically than deficit financing of undifferentiated expenditure. Keynes was aware of this and gave the political argument as one of the reasons (not the only one) for a bias in favour of investment spending." (Ibid, p. 214).

Por outro lado, a necessidade do uso dos recursos públicos em projetos de investimento tem por base a concepção de Keynes sobre a preferência pela liquidez e de que as flutuações nos investimentos são a causa causans do nível de atividade econômica e de emprego (Keynes, 1973, v. 14, p. 121). Nos textos de Keynes, há claras indicações de que ele se opunha a algumas políticas fiscais que produziram aumento de consumo e não dos investimentos.

"I doubt if it is wise to put too much stress on devices for causing the volume of consumption to fluctuate in preferences to devices for 
varying the volume of investment. People have established standards of life. Nothing will upset them more than to be subject to pressure constantly to vary them up and down [...] Moreover, the very reason that capital expenditure is capable of paying for itself makes it much better budgetwise and does not involve the progressive increase of budgetary difficulties, which budgeting for the sake of consumption may bring about." (Keynes, 1980, v. 27, pp. 319-320)

O programa de intervenção do Estado idealizado por Keynes para o pós-guerra previa investimentos estáveis de longo prazo entre $7,5 \%$ e $20 \%$ da renda disponível, sustentado por um orçamento de capital equilibrado no longo prazo. Ele acreditava que, se dois terços ou três quartos do investimento total fosse sustentado ou influenciado por "public and semi-public bodies", um programa de longo prazo seria capaz de reduzir substancialmente o grau de flutuação da economia e garantir um equilíbrio próximo ao pleno emprego (Ibid, p. 352).

Apesar da ousadia de seu plano para os países desenvolvidos no pós-guerra, Keynes deixa muito claro que sua proposta de expansão dos investimentos não tinha como objetivo criar um subterfúgio para encobrir os déficits (Ibid, p. 406). Além de rejeitar o aumento indiscriminado do gasto público, Keynes chega a sugerir a geração de superávits no orçamento ordinário para ser transferido para o orçamento de capital, "thus gradually replacing dead-weight debt by productive or semi-produtive debt" (Ibid, p. 277).

Segundo Kregel (1985, p. 46), Keynes teria priorizado as políticas de estabilização do nível de emprego, com investimentos, aos programas de transferência e manutenção dos níveis de renda. Mesmo suas recomendações de políticas tributárias de distribuição de renda tinham como objetivo central uma questão macroeconômica: reduzir a propensão média a poupar para ampliar os efeitos do multiplicador. A tradução da teoria keynesiana a partir do modelo IS-LM, entretanto, levou os formuladores da política econômica do pós-guerra a aplicarem de modo equivocado as recomendações de Keynes, não só na área fiscal, como também na área monetária, com taxas de juros cada vez mais elevadas, o que provocou a retração da atividade econômica e, por consequência, o aumento do déficit fiscal (Ibid).

Por outro lado, a implementação do Estado de bem-estar social nos países europeus fez crescer enormemente as despesas correntes as expensas das de capital, ao contrário do que era recomendado por Keynes. É interessante notar que, embora o welfare state esteja muitas vezes associado ao keynesianismo, sua montagem pelo Partido Trabalhista inglês foi inspirada no relatório de William Beveridge (1942), um economista de convicções liberais. Conforme Marcuzzo (2005, p. 3), os primeiros passos no sentido de introduzir as bases para um Estado de bem-estar social foram dados na reforma liberal de 1906-14, quando Beveridge assessorava o governo inglês. Sua completa imple- 
mentação, entretanto, ocorreu apenas com a legislação de 1944-48, em decorrência da experiência da Segunda Guerra Mundial.

"In the first decade of the $20^{\text {th }}$ century, the 'new liberalism' was an ideology based on the premise that, in order to advance individual freedom, the state must adopt an active role in social reform; the new measures resulted in the simultaneous introduction of old-age pensions, unemployment insurance, sickness benefits and progressive taxation" (Ibid, p. 4).

O paradoxo, segundo a autora, é que Beveridge formulou suas propostas com base na teoria ortodoxa que Keynes criticava, mas é importante lembrar que a economia do bem-estar tem origem na teoria neoclássica marginalista e utilitarista de Edgeworth. Dessa forma, Beveridge via a necessidade de um sistema de seguridade social porque acreditava que os recursos à disposição da economia eram escassos e que, portanto, era preciso introduzir algum mecanismo de realocação que maximizasse o bem-estar da sociedade (Marcuzzo, 2005, p. 7).

Keynes, ao contrário, via a necessidade de intervenção do Estado para estabilizar a demanda efetiva e "nunca foi um reformador social apaixonado" (Skidelsky, 2000, p. 265). Da mesma forma, Beveridge era um crítico contumaz da TG. Na década de 1940, entretanto, Keynes foi chamado por Beveridge para lhe assessorar na elaboração do plano de financiamento do sistema de seguridade social, motivo pelo qual o welfare state é até hoje visto como uma expressão do keynesianismo e da social-democracia.

Essas considerações de natureza histórica são importantes tanto para compreendermos o que Keynes realmente defendia quanto para, ao analisar a natureza da expansão dos gastos públicos no Brasil, sermos capazes de formular uma crítica heterodoxa consistente e, ao mesmo tempo, oferecer alternativas coerentes.

Neste sentido, podemos perceber, pela análise da origem da questão fiscal no Brasil e do ajuste procedido no caso brasileiro, que em ambos os casos não existe uma inspiração keynesiana. Muito pelo contrário: no primeiro caso, a origem do problema fiscal remonta ao endividamento externo e se agrava com a expansão de gastos que não deveriam ser privilegiados na concepção de Keynes, no segundo caso, a vocação do ajuste é de caráter eminentemente ortodoxo.

Em uma perspectiva keynesiana, dever-se-ia perseguir o equilíbrio fiscal no que tange as despesas correntes e usar os investimentos como forma de reduzir os impactos do ciclo na atividade econômica. Ao mesmo tempo, a estratégia de redução da dívida pública não deveria ser pautada apenas pela geração de superávit primário e nem no conceito de dívida líquida, mas pelo conceito de dívida bruta e pela utilização dos gastos em investimento e infraestrutura como elementos essenciais para o crescimento da economia. 


\section{CONSIDERAÇÕES FINAIS}

O esboço de um novo paradigma orçamentário e fiscal para o Brasil requer a definição de alguns princípios básicos. A noção de equilíbrio orçamentário tem sido associada a pressupostos neoclássicos, como o de que a oferta determina a demanda e de que a moeda é neutra pelo menos no longo prazo, de modo que todo e qualquer gasto público em excesso às receitas - isto é, todo e qualquer aumento do endividamento público - é uma fonte potencial de inflação ou de crowding out. Essa concepção influenciou a implementação do programa de ajuste fiscal no país e a adoção de metas de superávit primário como fundamento para atingir o equilíbrio fiscal e o controle do endividamento, sem distinguir os gastos públicos por sua natureza - corrente ou de capital - nem impor limites para a taxa de juros.

O regime de metas de superávit primário (e de inflação), embora relativamente bem-sucedido em controlar o nível de endividamento do setor público em comparação com a política fiscal anterior a 1999, teve um custo expressivo por: i) conjugar-se com uma política monetária restritiva; ii) processar-se pelo aumento da carga tributária; iii) derrubar o investimento público ao menor nível dos últimos 30 anos; iv) inibir parcialmente os investimentos privados, seja pelas deficiências na infraestrutura dependente das inversões do setor público, seja pelo alto patamar da taxa de juros; v) e implicar um ônus fiscal sobre a dívida muito superior ao que teria sido requerido com taxas de juros menores.

A questão relevante é de que modo podemos oferecer uma alternativa heterodoxa e viável ao atual padrão de ajuste fiscal. Em primeiro lugar, é preciso repensar o modelo macroeconômico de acordo com as evidências empíricas, que apontam no sentido de que taxas reais de juros elevadas são causa e não consequência dos déficits fiscais (Smithin, 1994). Em segundo lugar, é possível conciliar o princípio do equilíbrio fiscal com o pensamento de Keynes, dadas suas considerações para o período pós-guerra. Embora admitisse políticas deficitárias para lidar com situações de recessão profunda, como na crise de 1929, Keynes claramente manifestava preferência por um orçamento corrente equilibrado, chegando a sugerir sua separação do orçamento de capital.

"O orçamento de capital poderia ser deficitário, porém, o déficit em si não é um instrumento, mas sim um resultado dependente do comportamento das receitas de impostos, sendo estas função da velocidade com a qual a sociedade reage ao estímulo representado pelo incremento dado pelo governo aos investimentos" (Carvalho, 1999, p. 274).

Dessa forma, ao contrário dos ajustes de cunho ortodoxo, que penalizam os investimentos, o equilíbrio fiscal na perspectiva keynesiana deve se pautar pelo controle das despesas correntes e por um tratamento e financiamento diferenciado dos projetos de infraestrutura e outros fundamentais para a elevação da capacidade produtiva. A manutenção de um patamar elevado de investimentos públicos ou semipúblicos é essencial não só para dar suporte aos investimentos privados, em áreas complementares, como também se justifica 
por razões macroeconômicas, como evitar flutuações indesejáveis do produto (Kregel, 1985) e, principalmente, melhorar a performance de longo prazo da economia (Smithin, 1989).

Por seu efeito multiplicador na economia, os investimentos públicos têm a capacidade de se autofinanciar no médio e no longo prazo e podem ser colocados em prática sem a necessidade de poupança prévia, mas evidentemente seu patamar estará, pelo menos parcialmente, limitado por outras variáveis fiscais, como o peso crescente das transferências previdenciárias e assistenciais no orçamento. Uma interpretação forçada de Keynes e de sua já mencionada falta de entusiasmo pelos programas sociais (Skidelsky, 2000) poderia sugerir a necessidade de cortes drásticos no orçamento corrente e de reformas na seguridade social com vistas a abrir espaço para os investimentos. Contudo, suas considerações para a economia europeia do pós-guerra não podem ser mecanicamente transpostas para o Brasil, um país com enorme contingente de miseráveis e uma das distribuições de renda mais desiguais do planeta.

Apesar da necessidade de discutir melhor a estrutura de financiamento para a rede de proteção social e reorientar a política econômica de modo a criar as bases para um crescimento mais sustentado e menos dependente de medidas paliativas, não podemos confundir o custo do welfare state com o dos demais gastos correntes. As transferências monetárias do governo às pessoas devem ser consideradas em conjunto com o sistema de tributação, pelo papel que cumprem na redistribuição de renda e por reporem a renda disponível subtraída pelos tributos.

Por outro lado, não há como negar que, em um país com o nível de endividamento do Brasil, a política fiscal sofre sérias restrições, inclusive de natureza política. O peso da dívida pública confere um poder de grande magnitude aos detentores dos títulos públicos, sobretudo os intermediários do sistema financeiro. Os bancos são capazes de detonar uma crise financeira e cambial por simples avaliações subjetivas sobre a política econômica, particularmente quando esta contraria seus interesses.

Nesse contexto, uma plataforma heterodoxa também pode ter como uma de suas metas a redução da dívida pública, mas não nos marcos da atual política fiscal, que objetiva apenas a redução do endividamento líquido e sanciona a taxa de juros definida pelo Banco Central. É impossível qualquer pretensão de zerar o déficit fiscal no Brasil, mesmo que restrito ao orçamento corrente, enquanto o custo dos juros também não for drasticamente reduzido. Isso não significa, entretanto, abdicar dos superávits primários como forma de conter o endividamento, embora seja cabível uma discussão sobre sua calibragem e sobre os efeitos dinâmicos dos investimentos no equilíbrio de longo prazo.

Não há justificativa, por exemplo, para o fato de o governo não estar utilizando a margem permitida atualmente pelo Projeto Piloto de Investimentos $(0,5 \%$ do PIB) para reduzir o superávit primário, principalmente se considerarmos a atual trajetória de queda da dívida líquida. É plenamente possível reduzir o superávit primário e, ainda assim, manter o endividamento em queda. 
As empresas do setor produtivo estatal (SPE) também podem cumprir um papel importante nesse plano de investimentos, a exemplo dos organismos autônomos ou semipúblicos imaginados por Keynes. Atualmente, elas já têm executado um volume considerável de inversões, principalmente no setor do petróleo, mas muitas vezes seus planos são restringidos pela necessidade de contribuir para o superávit primário mesmo não tendo encargos de dívida a pagar. Atualmente, a dívida líquida das estatais é "negativa”, como indicam os relatórios fiscais do Banco Central, não justificando-se que as mesmas tenham seus investimentos contidos a pretexto de contribuir para a redução do endividamento líquido do setor público.

\section{REFERÊNCIAS BIBLIOGRÁFICAS}

AVERBUG, A.; GIAMBIAGI, F. (2000) “A crise brasileira de 1998/1999: Origens e consequências”. Texto para Discussão BNDES n 77.

BACEN (2007) Boletim, Seção Finanças Públicas. Brasília: Banco Central do Brasil.

BARROS, R.P.; HENRIQUES, R.; MENDONÇA, R. (2001) "Desigualdade e pobreza no Brasil: Retrato de uma estabilidade inaceitável. Texto para Discussão IPEA n ${ }^{\circ} 800$.

BEVERIDGE, W. B. (1942) Social Insurance and Allied Services. London: HMSO.

BIASOTO Jr., G. (2006) “A polêmica sobre o déficit público e a sustentabilidade da política fiscal”. In Pinto, Márcio P. A. e Biasoto Jr., Geraldo, orgs. Política Fiscal e Desenvolvimento no Brasil. Campinas: IE/Unicamp.

BRESSER-PEREIRA, L.C.; DALL'ACQUA, F. (1991) "Economic populism versus Keynes: Reinterpreting budget deficit in Latin America", Journal of Post-Keynesian Economics 14(1), p. 29-38.

BRESSER-PEREIRA, L.C. (2004) “Macroeconomia pós-Plano Real: As relações básicas”, in João Sicsú, Luiz Fernando de Paula e Renaut Michel, orgs., Novo Desenvolvimentismo: Um Projeto Nacional de Crescimento com Equidade Social. Barueri: Manole; Rio de Janeiro: Fundação Konrad Adenauer.

CARVALHO, F.C. (1999) “Políticas econômicas para economias monetárias”, In Gilberto Tadeu Lima, João Sicsú e Luiz Fernando de Paula, orgs. Macroeconomia Moderna: Keynes e a Economia Contemporânea. Rio de Janeiro: Editora Campus.

COUTINHO, L. e BELLUZZO, L.G. (1984) “Política econômica, inflexões e crise: 1974-1981", in Belluzzo, L.G. e Coutinho, R., orgs. Desenvolvimento Capitalista no Brasil: Ensaios sobre a Crise. São Paulo: Editora Brasiliense.

CRUZ, P.D. (1984) Dívida Externa e Política Econômica: a experiência brasileira nos anos setenta. São Paulo: Editora Brasiliense.

DAVIDSON, P. (1991) "The neoclassical vs. post Keynesian view of government", in Controversies in Post Keynesian Economics. Aldershot, UK: Edward Elgar.

DELFIM NETTO, A. (2005) "Déficit nominal zero", Boletim de Conjuntura Economia \& Tecnologia, ano 1 , v. 2, p. 5-12.

FERRARI FILHO, F., (2005) “As concepções teórico-analíticas e as proposições de política econômica em Keynes”. Revista de Economia Contemporânea, Vol. 10, n 2, p. 213-36.

FRANCO, G. (1995) "A crise fiscal da união: Diagnóstico e apontamentos para uma Lei das Finanças Públicas”, in G. Franco, O Plano Real e Outros Ensaios. Rio de Janeiro: Francisco Alves.

GIAMBIAGI, F. (2005) "Em defesa de um superávit primário de 5\% do PIB”, Revista Desafios do Desenvolvimento, $\mathrm{n}^{\circ} 14$.

KEYNES, J. M. (1973) The General Theory and After. Part I. Preparation. Vol. 13. London: MacMillan. 
KEYNES, J. M. (1973) The General Theory and After. Part II. Defence and Development. Vol. 14. London: MacMillan.

KEYNES, J. M. (1979) The General Theory And After: A Supplement. The Collected Writings of John Maynard Keynes. Vol. 29. London: MacMillan.

KEYNES, J. M. (1980) Activities 1940-1946 shaping the Post-War World: Employment and Commodities. Vol. 27. London: MacMillan.

KEYNES, J. M. (1982) A Teoria Geral do Emprego, do Juro e da Moeda. São Paulo: Editiora Atlas.

KREGEL, J. (1985) "Budget deficits, stabilisation policy and liquidity preference: Keynes's post-war policy proposals", in VICARELLI, F., ed. Keynes's Relevance Today. London: Macmillan.

MARCUZZO, M.C. (2005) "Keynes and the welfare state". Preliminary Draft. Universidade de Roma. Disponível em: www2u.biglobe.ne.jp/ olympa/cambridge/hyoushi/marcuzzo.doc.

SERVÉN, L. (2004) "Déficit público, espació fiscal e inversión em infraestructura". Anais da Reunião Latino-americana sobre Financiamento de Infraestrutura. Disponível em: www.alide.org.pe/download/CEDOM/Infraestructura_AS2003/politica.htm. Buenos Aires: ALADI.

SIMONSEN, M.H. (1989) “A conta-corrente do governo: 1970-1988”, Ensaios Econômicos, n 136.

SKIDELSKY, R. (2000) John Maynard Keynes. Fighting for Britain. London: MacMillan.

SMITHIN, J.N. (1989) “The composition of government expenditures”, in John Pheby, org. New Directions in Post-keynesian Economics. Aldershot, UK: Edward Elgar.

SMITHIN, J.N. (1994) "Cause and effect in the relationship between budget deficits and the rate of interest”. Economies et Societes, Série MP 9, v. 28, nº 1-2/1994, p. 151-169. Paris: Isméa.

WERNECK, R. (1986) "Poupança estatal, dívida externa e crise financeira do setor público", Pesquisa e Planejamento Econômico, 16 (3): 551-74. 